\section{RESOLVE}

N E T W O R K

\section{FACT/SHEET}

COMMUNITY BASED

ARMED GROUPS

\title{
Origins of Hybrid Governance and Armed Community Mobilization in Sub-Saharan Africa
}

This fact sheet provides a snapshot of conclusions from the mapping effort of the RESOLVE Network's Community-Based Armed Groups Research Initiative that investigates the dynamics of communitybased armed groups (CBAGs) to identify potential approaches to engage, manage, and transform them. This Research Report explores the origins, dynamics, and drivers of CBAGs in Africa and clarifies the multiplicity and complex relationships between these groups and the state, as well as their prominent roles and responsibilities in security provision and service delivery. Discussions with stakeholders and a critical review of the literature revealed the need for research to go beyond the narrative of CBAGs as national security threats and consider their roles as contributors to state-building and peace-building. To learn more about the research methodology, detailed findings, and illustrative case studies, please refer to the RESOLVE Research Report by Daniel E. Agbiboa: Origins of Hybrid Governance and Armed Community Mobilization in Sub-Saharan Africa.

\section{Colonial Police Legacy}

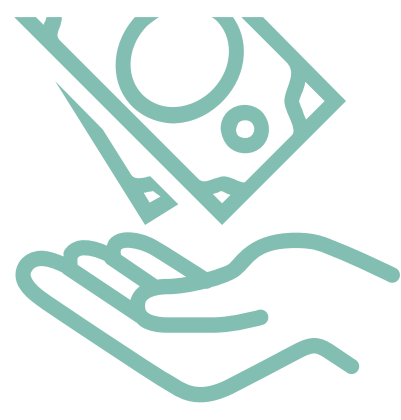

»Colonial police forces relied on coercion rather than authority for compliance. This pattern has continued in postcolonial Africa, where state police forces are often perceived as corrupt and unconnected to the communities they serve.

\section{Self-help Groups}

» The negative perception of state police forces has fueled the rise of self-help groups (for example, vigilantes, militias, and gangs), some of whom exist to challenge predatory and unaccountable modes of governance.

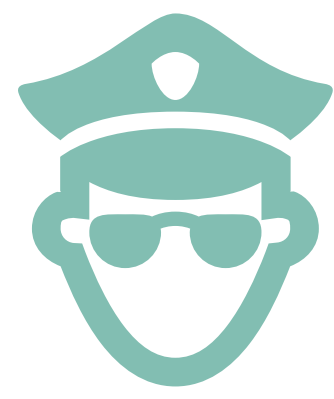




\section{Community Policing}

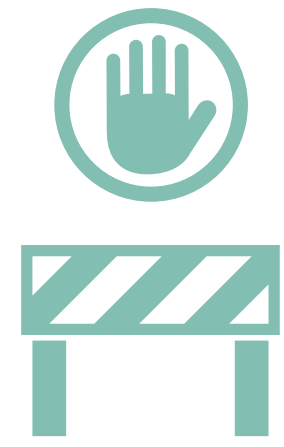

» Given the financial, logistical, and knowledge constraints of the colonial state-which would qualify it as a "weak state"-a prevailing ideology emerged that emphasized the responsibility of the African community to police itself.

\section{Turning to CBAGs}

» Failing states in postcolonial Africa increasingly turn to CBAGs to maintain law and order due to their perceived cost-saving measures, effectiveness, or popular legitimacy.

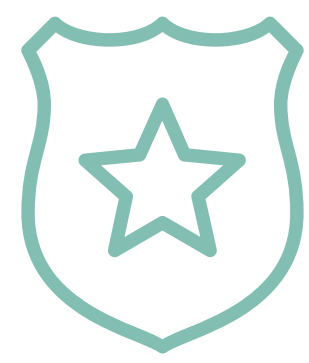

\section{Key Takeaways}

» The emergence of CBAGs does not necessarily spell doom for the authority of the state; it can help the state expand and rebuild trust in formal institutions.

» A hybrid security approach can foster a sense of local ownership and agency for managing various security threats to daily life.

» Early and ongoing oversight and accountability mechanisms can reduce the chances that CBAGs will morph into predators.

» The rise of CBAGs necessitates state forces that are part of the community and accountable to it. State security forces need to understand the local culture and language of the communities they serve. This will help to develop the trust, reciprocity, and local legitimacy of the police and courts system for effective and responsible security provision.

» Any effort to address CBAGs must include reconfiguring the everyday culture and practice of bribery, corruption, and abusive policing in Africa.

\section{RESOLVE Network}

better research.informed practice.improved policy on violent extremism.

UNITED STATES

Institute of PeAce Making Peace Possible 